\title{
STUDY ON THE MECHANICAL PROPERTIES OF A TYPE OF SPHERICAL BEARING ${ }^{1}$
}

\author{
YINGFANG YANG \\ Southwest Jiaotong University, School of Civil Engineering, China, and \\ Central Research Institute of Building and Construction Co., Ltd. MCC, China \\ YAN ZHANG, JINSAN JU \\ China Agricultural University, Department of Civil Engineering, Beijing, China \\ e-mail: jujinsan@cau.edu.cn (Jinsan Ju)
}

\begin{abstract}
The spherical bearing is widely used in highways, bridges and long-span structures. In order to study mechanical properties of a large-scale spherical bearing, a full-scale finite element model of the spherical bearing was established by using ABAQUS software, and the mechanical properties of the spherical bearing under four working conditions were simulated respectively when the upper bearing plate had different inclination angles. The ultimate bearing capacity of the spherical bearing under vertical tension was analyzed emphatically. The research results show that, in practical applications, the change in bearing capacity caused by the inclination angle of the upper bearing plate should be considered, and the wedge-shaped part should be strengthened.
\end{abstract}

Keywords: spherical bearing, finite element, mechanical properties, face contact

\section{Introduction}

The bearing is an important connecting part between an upper and lower structure. It must be able to support the load from the upper structure and transfer it to the lower structure stably (He, 2011), so that the actual stress situations of the upper and lower structure conform to the design structural calculation diagram ( $\mathrm{Li}, 2006)$. Before the 1960s, almost all bridge bearings were steel bearings and reinforced concrete bearings. With the development of the chemical industry, basin rubber bearings and plate rubber bearings appeared (He, 2011; Li, 2006). The spherical bearing is a new type of bearing developed on the basis of the basin rubber bearing, which belongs to a kind of steel bearing. Because there is no rubber material in the spherical bearing, there is no problem of affecting the performance of the bearing due to the aging of rubber (Shen and Akesson, 1998; Paver, 2006; Turkington et al., 1989; Block and Wölfel, 2004). The spherical bearing is widely used in highways, bridges and long-span structures because of the advantages of long service life, large bearing capacity, flexible rotation and adaptability to large rotation angles and large displacements of beam ends (Zang, 2009; Shao, 2002; Wang et al., 2002; Cui and $\mathrm{Xu}, 2000)$.

The spherical bearing in the engineering structure is in a complex state of stress. In addition to bearing gravity load and temperature, it is also controlled by wind loads and earthquake actions (Shen et al., 2011). Under the action of earthquake and temperature, the bearing may bear large horizontal forces, while under the action of wind loads, the bearing may bear large wind suction forces (Shen et al., 2011; Peng et al., 2007; Shi et al., 2009). However, the traditional spherical bearing is mainly designed to transfer vertical load, and its rotation capacity under a

\footnotetext{
${ }^{1}$ Presented paper from the 4th International Conference on Material Strength and Applied Mechanics, MSAM 2021
} 
horizontal force and its anti-pulling performance under a tensile force are poor (Wang and Xu, 2002; Cui and Xu, 2000; Peng et al., 2007; Shi et al., 2009).

The research on spherical bearings is mainly carried out by means of experiments and numerical analysis. Li (2006) designed the super large-tonnage spherical bearing from the bearing structure and tested it by finite element analysis. The mechanical performance of the bearing was improved by using a guide block structure. From the perspective of structural design, Zang (2009) elaborated the durability design of a large-tonnage and large-displacement spherical bearing, the connection between bearings and beam ends and piers, and the selection of the sliding plate material. Shen et al. (2011) proposed an improvement measure for the traditional spherical bearing which improved the rotation capacity of the bearing, and carried out design checking calculations and tests on the bearing under various stress states. Luo et al. (2013) studied a kind of anti-pull-out spherical bearing and analyzed the anti-pulling effect of the bearing by establishing a model, and applied mechanical check through the finite element method. Yan (2013) carried out the structural design and calculation of the spherical bearing, and put forward the stress check standard and design control factors of the spherical slide. He et al. (2012) used the finite element analysis method to analyze the conventional spherical bearing and obtained the deformation and stress distribution of each part of the bearing. Wang et al. (2019) proposed a new type of anti-pulling unidirectional sliding spherical bearing. The mechanical properties of the new type of bearing and the traditional bearing were compared by finite element analysis. The results showed the superiority of the mechanical properties of the new type of spherical bearing. By combining experiments and numerical simulation, Kamenskikh (2018) conducted correlation analysis on the deformation behavior of polymer antifriction layer materials with spherical bearings. The results showed that the modified polymer antifriction layer was more beneficial to the distribution of contact parameters.

Obviously, the current research on the spherical bearing mainly focuses on the structural design and checking calculations under different stress states. However, in actual engineering, due to the complexity of structures, the spherical bearing often needs to produce a certain deflection angle to fully execute its connection function. The existence of deflection angle makes the stress state of the spherical bearing more complex and affects its mechanical properties. There are few research data about the influence of the deflection angle on mechanical properties of the spherical bearing, especially on the bearing capacity. Therefore, it is of great scientific and practical significance to study the mechanical properties of spherical bearings under various working conditions with different deflection angles.

In this paper, according to the shortcomings of traditional spherical bearing design, the finite element method will be used to analyze the mechanical properties of the spherical bearing when there is relative rotation between the upper bearing plate and the ball core, that is, when the bearing has a deflection angle, so as to provide a reference for the design and calculation of the spherical bearing.

\section{Basic structure of the spherical bearing}

The traditional spherical bearing is mainly composed of the upper bearing plate, the ball core, the flat polytetrafluoroethylene (PTFE) plate, the spherical PTFE plate and the lower bearing plate, etc. (He et al., 2012). The flat sliding function is realized by the plane wear-resistant plate, and the rotation function is realized by the spherical wear-resistant plate (Luo et al., 2013). In addition to the basic structure of the traditional spherical bearing, the spherical bearing proposed in this paper connects the upper bearing plate and the lower bearing plate through four wedge-shaped parts (as shown in Fig. 1), which improves the anti-pulling performance of the bearing, and allows $0^{\circ}-3^{\circ}$ rotation between the upper bearing plate and the ball core (Fig. 2), which 
improves the rotation capacity of the bearing. When the rotation angle of the bearing exists, the installation balance of the bearing is determined by ensuring that the geometric center position of the upper bearing plate and the ball core coincide.

(a)

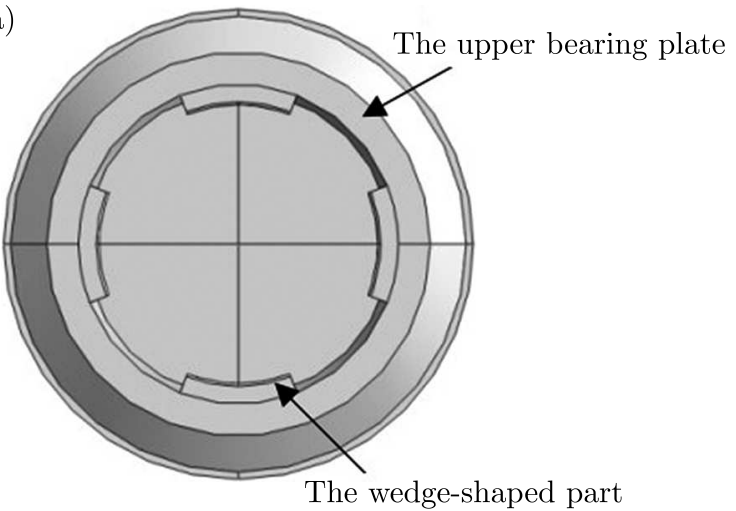

(b)

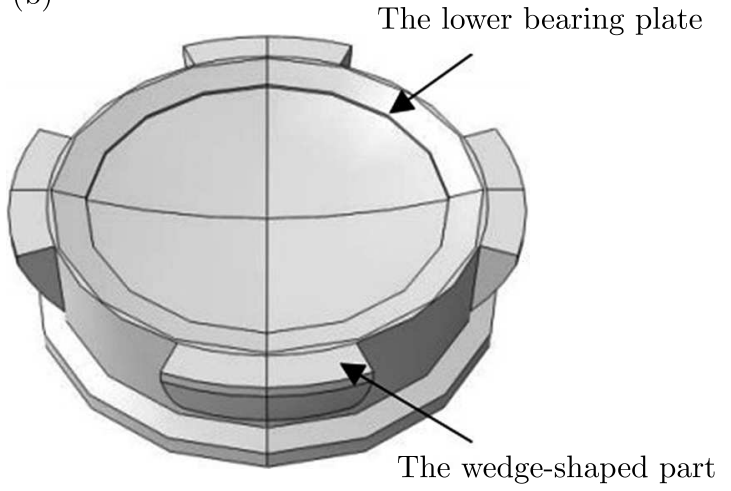

(c)

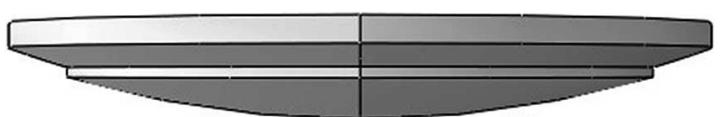

Fig. 1. Schematic diagram of the spherical bearing: (a) model of the upper bearing plate, (b) model of the lower bearing plate, (c) model of the ball core

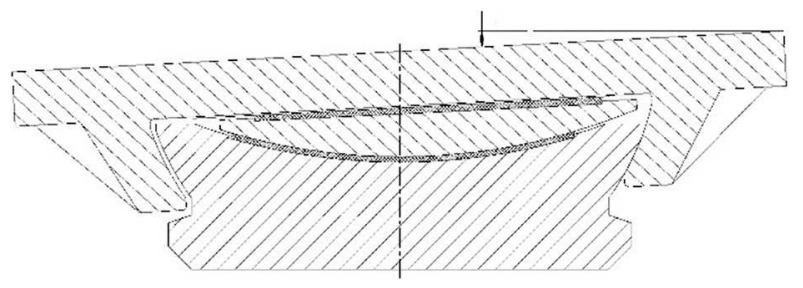

Fig. 2. Schematic diagram of the spherical bearing rotation angle

\section{Finite element model}

\subsection{Geometrical dimensions and material properties}

A 3D model of the new spherical bearing was established by CAD, and then the model was imported into ABAQUS software for finite element analysis. The specific size of the bearing is shown in Fig. 3. The main design basis of the spherical bearing was Code for Seismic Design of Buildings - GB 50011-2010 (Code for Seismic Design of Buildings 2016), Standard for Design of Steel Structures - GB 500017-2017 (Standard for Design of Steel Structures 2018), Technical Specification for Application of Connections of Structural Steel Casting - CECS235: 2008 (Technical Specification for Application of Connections of Structural Steel Casting 2008) and Spherical Bearing for Steel Building - GB/T32836-2018 (Ministry of Housing and Urban-Rural Development of the People's Republic of China 2017).

The upper bearing plate, the ball core and the lower bearing plate were made of cast steel G20Mn5QT. The mechanical properties of the cast steel G20Mn5QT were adopted from the test results in the literature (Huang, 2018). The double-broken line constitutive model was used as the material constitutive relationship, and the elastic modulus $E=2.17 \cdot 10^{5} \mathrm{MPa}$, yield strength $\sigma_{s}=503.7 \mathrm{MPa}$, ultimate strength $f_{u}=624.5 \mathrm{MPa}$. 


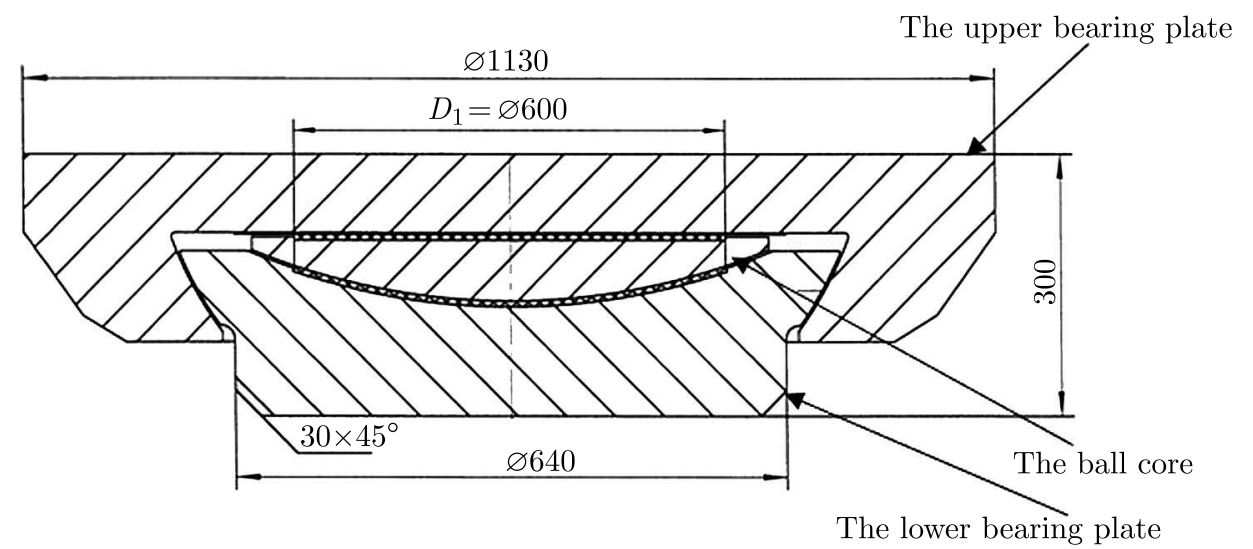

Fig. 3. Dimensions of the spherical bearing

\subsection{Contact and restraint settings}

In the actual working state, the upper bearing plate, the lower bearing plate and the ball core are not completely fixed, and thus sliding displacement is allowed. In the finite element analysis, the surface-to-surface contact method was used for the correlation between various parts of the bearing so as to better simulate the actual working state (Liu et al., 2019). Under the contact, the type of friction was defined by normal, tangential and geometric behavior, and the friction coefficient of the penalty function was defined in the tangential behavior, in which the friction coefficient of the upper and lower bearing plate was 0.2. The friction coefficient of the ball core and the upper and lower bearing plates were 0.03, taking into account the actual contact state of each bearing part in the working state.

The bottom of the lower bearing plate was restrained by the fixed end, and the vertical pressure, vertical tension and shear force were realized by applying a surface load on the upper surface of the upper bearing plate.

\subsection{Element and mesh division}

By cutting the assembly and setting the edge seeds, a mesh division was guaranteed to be as regular as possible, and the mesh quality was improved. The total number of model elements was 33792 , and the smallest element was located at the wedge-shaped parts of the bearing with a size of about $2.98 \mathrm{~mm}$. Element C3D8R provided in ABAQUS was used in the model, which is an eight-node linear hexahedral element and can obtain accurate simulation results under the premise of ensuring sufficient mesh density.

\subsection{Load cases}

According to the "Spherical Bearing for Steel Building Structure" specification and combined with the actual working conditions of the spherical bearing, the following five working states were determined, among which working state 5 was used to determine the ultimate bearing capacity of the bearing under different rotation angles. A schematic diagram of load application under various working conditions is shown in Fig. 4. (1) Working state 1, vertical pressure of $3400 \mathrm{kN}$; (2) working state 2, vertical tension of $6600 \mathrm{kN}$; (3) working state 3, vertical pressure of $3400 \mathrm{kN}$ and shear force of $2000 \mathrm{kN}$; (4) working state 4, vertical tensile force of $6600 \mathrm{kN}$ and shear force of $1500 \mathrm{kN}$; (5) working state 5, vertical tension of $60000 \mathrm{kN}$. 
(a)

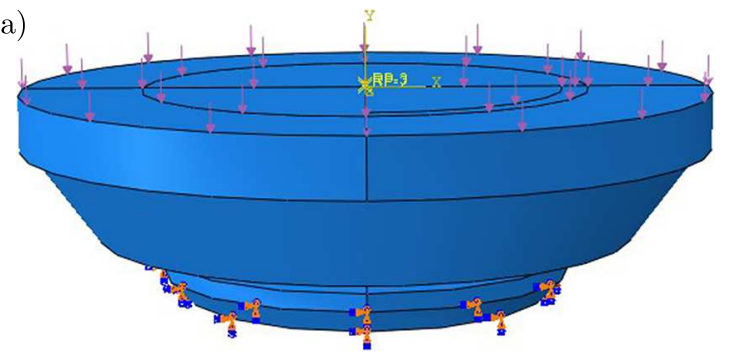

(c)

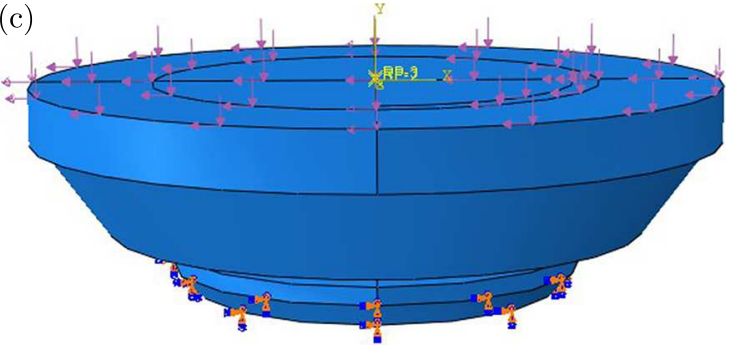

(b)

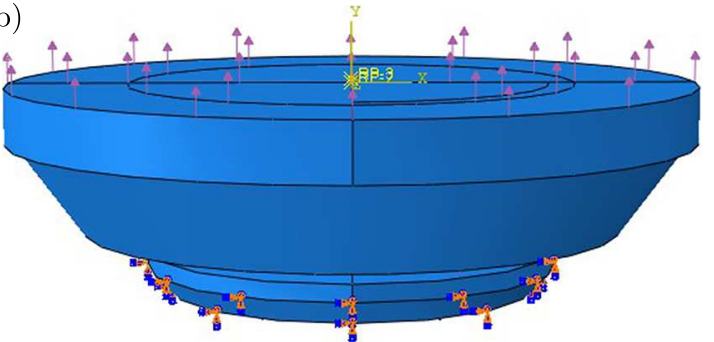

(d)

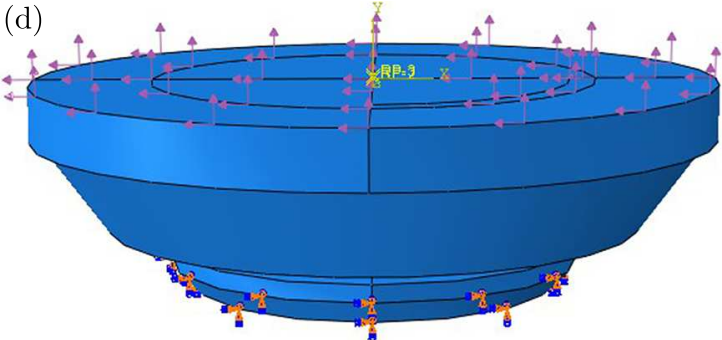

(e)

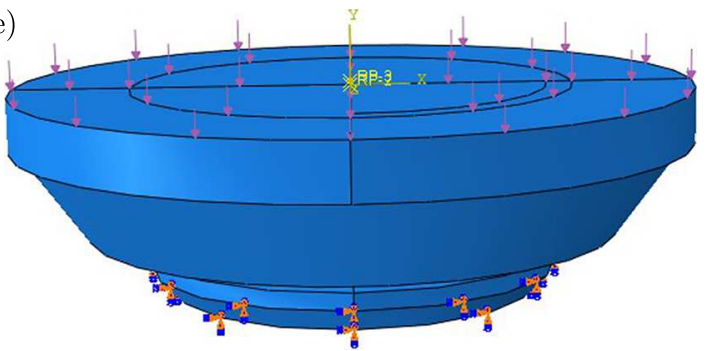

Fig. 4. Diagram of the bearing load: (a) working state 1, (b) working state 2, (c) working state 3, (d) working state 4 , (e) working state 5

\section{Results analysis}

\subsection{Under the action of vertical pressure}

In order to simulate the actual working state, the design load was applied to the upper surface of the upper bearing plate (i.e. working state 1 ). The stress cloud diagrams of each part of the spherical bearing are shown in Fig. 5. Under the action of vertical pressure, the load transmission path of the bearing is from the external force to the upper bearing plate, then to the ball core and finally to the lower bearing plate.

It can be seen from Fig. 5 that under the action of vertical pressure, the maximum stress of the bearing appears in the lower bearing plate with a maximum stress value of $152.8 \mathrm{MPa}$, followed by the ball core, and the maximum stress value at the ball core is $132.7 \mathrm{MPa}$. Obviously, under the action of vertical pressure, the most unfavorable position of the bearing is the lower bearing plate, and the stress of each part is all less than the yield strength of the material, which meets the design requirements.

Under the same vertical pressure, the change of the maximum stress of the bearing was calculated when the inclination angles of the upper bearing plate were $0^{\circ}, 1^{\circ}, 2^{\circ}$, and $3^{\circ}$. Under the action of vertical pressure, when the inclination angles of the upper bearing plate were $0^{\circ}, 1^{\circ}$, $2^{\circ}$, and $3^{\circ}$, the maximum stress of the bearing was $153 \mathrm{MPa}, 353 \mathrm{MPa}, 354 \mathrm{MPa}$ and $355 \mathrm{MPa}$, respectively. The comparative analysis shows that when the vertical pressure is constant, the maximum stress of the bearing increases with the increase of the inclination angle of the upper bearing plate. When the inclination angle of the bearing changes from $0^{\circ}$ to $1^{\circ}$, the maximum stress of the bearing changes greatly. When the upper bearing plate has an inclination angle, the 
(a)

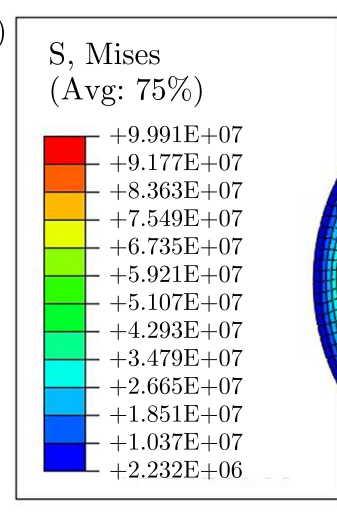

(b)

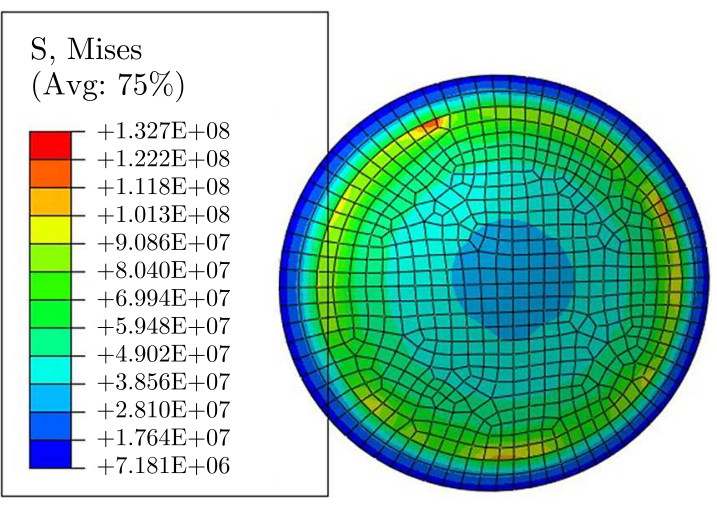

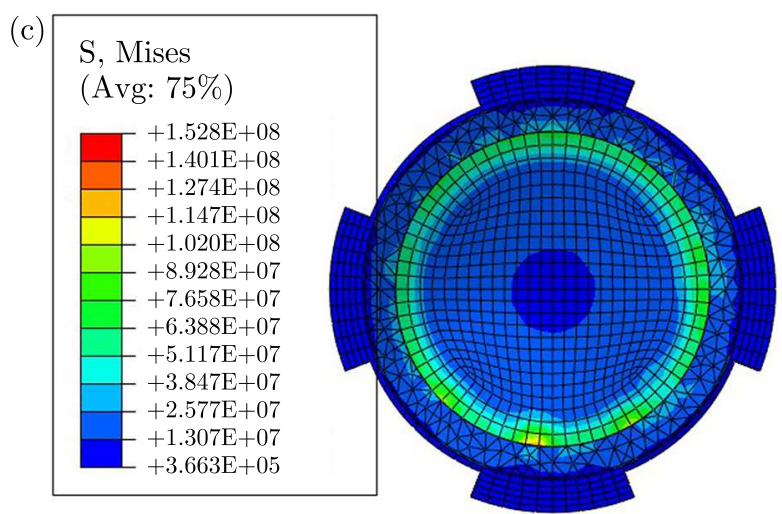

Fig. 5. Stress cloud diagram of each part of the bearing under vertical pressure: (a) upper bearing plate, (b) ball core, (c) lower bearing plate

position where the maximum stress occurs on the bearing has nothing to do with the inclination angle of the upper bearing plate, and the maximum stress occurs in the ball core part.

\subsection{Under the action of vertical tension}

In order to simulate the actual working state, the design load was applied to the upper surface of the upper bearing plate (i.e. working state 2). The stress cloud diagrams of each part of the spherical bearing are shown in Fig. 6. Under the action of vertical tension, the force transmission path of the bearing is from the external force to the upper bearing plate and finally to the lower bearing plate. Because the ball core is not stressed under the effect of the tensile force, the stress cloud diagram of the ball core is not given.

(a)

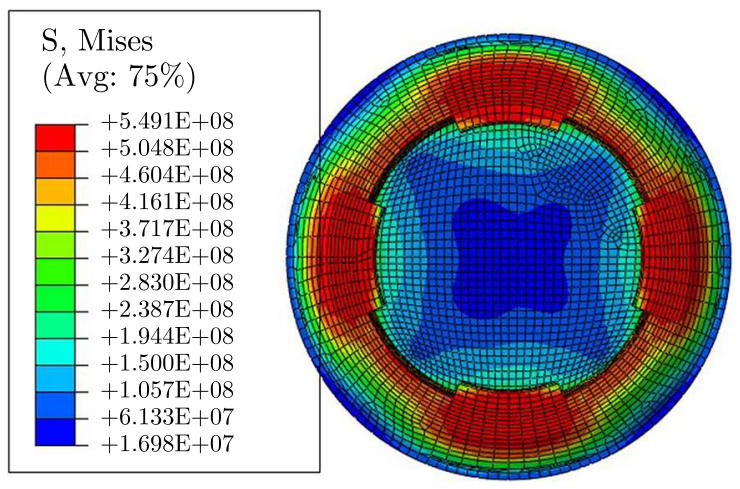

(b)

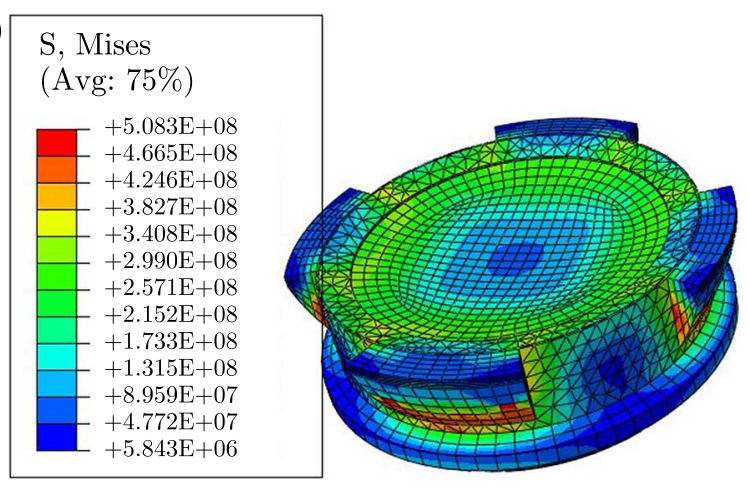

Fig. 6. Stress cloud diagram of each part of the bearing under vertical tension: (a) upper bearing plate, (b) lower bearing plate 
It can be seen from Fig. 6 that under the action of vertical tension, the maximum stress of the spherical bearing is $549 \mathrm{MPa}$, which appears in the wedge-shaped part of the upper bearing plate, and the material enters plasticity. This is because under the action of vertical tension, the external force is transmitted to the lower bearing plate through the upper bearing plate, and the upper and lower bearing plates are occluded through the wedge-shaped part, so it is easy for stress concentration occurring at the wedge-shaped part. The maximum stress of the lower bearing plate is $508 \mathrm{MPa}$, which appears at the wedge-shaped part where the lower and upper bearing plates are connected.

Under the same vertical tension, the maximum stress of the bearing was calculated when the inclination angles of the upper bearing plate were $0^{\circ}, 1^{\circ}, 2^{\circ}$ and $3^{\circ}$. Under the action of vertical tension, when the inclination angles of the upper bearing plate are $0^{\circ}, 1^{\circ}, 2^{\circ}$ and $3^{\circ}$, the maximum stress of the bearing is $549 \mathrm{MPa}, 558 \mathrm{MPa}, 562 \mathrm{MPa}$, and $545 \mathrm{MPa}$, respectively. The comparative analysis shows that when the inclination angle changes from $0^{\circ}$ to $3^{\circ}$ and under the same tensile force, the stress of the bearing is up to the maximum value when the upper bearing plate is inclined at $2^{\circ}$. Obviously, the inclination angle of $2^{\circ}$ is the most unfavorable stress angle of the bearing under the tensile force. Under the action of the tensile force, the occlusion of the upper and lower bearing plates is mainly realized through the wedge-shaped parts, so the maximum stress of the bearing always appears in the wedge-shaped parts of the upper bearing plate, and the elements at the wedge-shaped part enter plasticity.

\subsection{Under the combined action of vertical pressure and shear force}

In order to simulate the actual working state, the design load was applied to the upper surface of the upper bearing plate (i.e. working state 3 ). The vertical pressure and shear force were applied in the same analysis step, and the shear force was always parallel to the surface of the upper bearing plate. When the upper bearing plate is not inclined, the stress cloud diagrams of each part of the bearing under the combined action of vertical pressure and shear force are shown in Fig. 7.

It can be seen from Fig. 7 that under the combined action of vertical pressure and shear force, the maximum stress of the bearing is $182 \mathrm{MPa}$, which appears in the lower bearing plate, and then occurs at the contact position between the ball core and the lower bearing plate, and the stress is $174 \mathrm{MPa}$. The action of the shear force makes one side of the bearing bear more stressed than the other side, so the stress cloud diagrams of each part of the bearing exhibit a phenomenon of larger stress on one side and smaller stress on the other side.

Table 1. The maximum stress of the bearing

\begin{tabular}{|c|c|c|c|}
\hline $\begin{array}{c}\text { Shear } \begin{array}{c}\text { force } \\
\text { direction }\end{array} \\
\text { doting }\end{array}$ & $\begin{array}{c}\text { Inclination } \\
\text { bearing plate }\left[{ }^{\circ}\right]\end{array}$ & $\begin{array}{c}\text { Maximum } \\
\text { stress of the } \\
\text { bearing [MPa] }\end{array}$ & $\begin{array}{c}\text { Location of } \\
\text { maximum } \\
\text { stress }\end{array}$ \\
\hline \hline \multirow{4}{*}{$X$} & 0 & 182 & Lower bearing plate \\
\cline { 2 - 4 } & 1 & 394 & Ball core \\
\cline { 2 - 4 } & 2 & 390 & Ball core \\
\cline { 2 - 4 } & 3 & 385 & Ball core \\
\hline \multirow{4}{*}{$-X$} & 0 & 167 & Upper bearing plate \\
\cline { 2 - 4 } & 1 & 313 & Ball core \\
\cline { 2 - 4 } & 2 & 316 & Ball core \\
\cline { 2 - 4 } & 3 & 362 & Ball core \\
\hline
\end{tabular}

Under the same vertical pressure and shear force, the maximum stress of the bearing varies with the inclination angle of the upper bearing plate as shown in Table 1. It can be seen that 
(a)

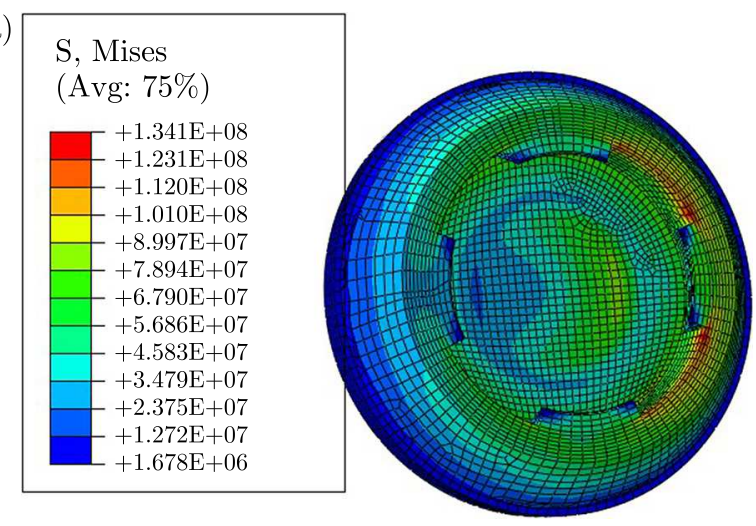

(b)

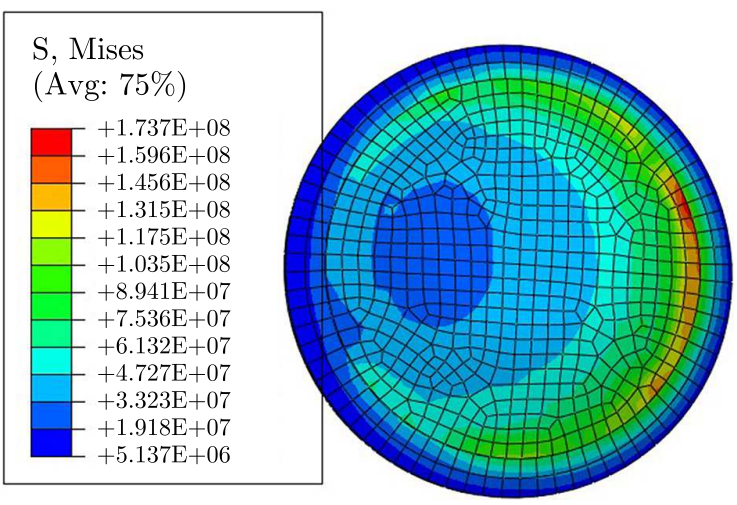

(c)

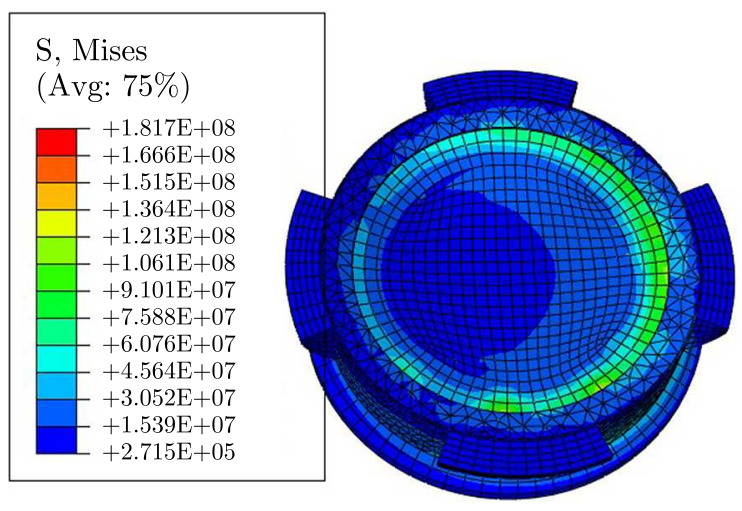

Fig. 7. Stress cloud diagram of each part of the bearing under the combined action of vertical pressure and shear force: (a) upper bearing plate, (b) ball core, (c) lower bearing plate

(a)

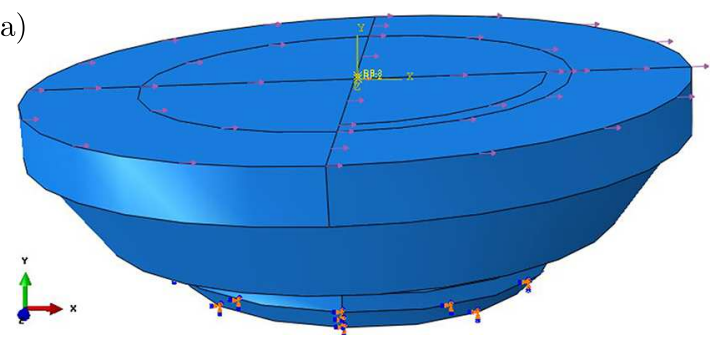

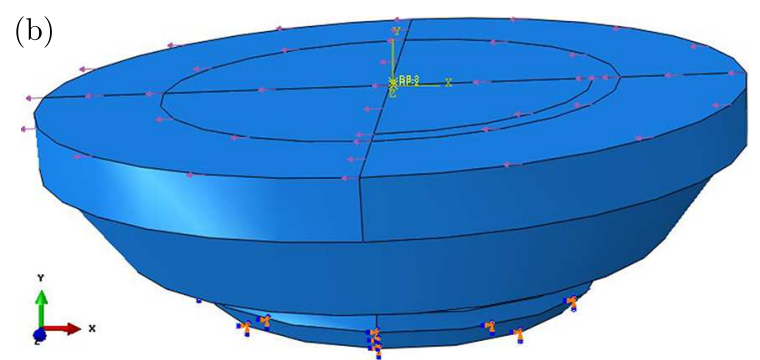

Fig. 8. Schematic diagram of the direction of the shear force: (a) opposite to the inclined direction, (b) consistent with the inclined direction

when the shear force direction is opposite to the inclined direction of the upper bearing plate (Fig. 8a), the maximum stress of the bearing decreases with the increase of the inclination angle of the upper bearing plate. When the shear force direction is consistent with the inclined direction of the upper bearing plate (Fig. 8b), the maximum stress of the bearing increases with the increase of the inclination angle of the upper bearing plate. The comparative analysis shows that under the combined action of vertical pressure and shear force, the inclination of the upper bearing plate increases the maximum stress of the bearing, and the most unfavorable force positions of the bearing are both located at the ball core and the lower bearing plate.

\subsection{Under the combined action of vertical tension and shear force}

In order to simulate the actual working state, the design load was applied to the upper surface of the upper bearing plate (i.e. working state 4). The tensile and shear force were applied in the same analysis step, and the shear force was always parallel to the surface of the upper bearing 
plate. The stress cloud diagrams of each part of the spherical bearing are shown in Fig. 9. Under the combined action of vertical tension and shear force, the maximum stress of the bearing is $564 \mathrm{MPa}$, which appears in the wedge-shaped part of the upper bearing plate, and the maximum stress of the lower bearing plate is $532.7 \mathrm{MPa}$, which appears in the wedge-shaped part of one side. This is because under the combined action of the tensile and shear force, the upper and lower bearing plates are occluded through the wedge-shaped parts, the wedge-shaped parts are under greater stress, and it is easy to produce stress concentration. Therefore, the maximum stress of the upper and lower bearing plates both appears in the wedge-shaped parts. Under the shear force, the stress on one side of the bearing is larger, while the stress on the other side is smaller. Therefore, the stress cloud diagrams of each part of the bearing present a phenomenon that the stress on one side is larger and the stress on the other side is smaller.

(a)

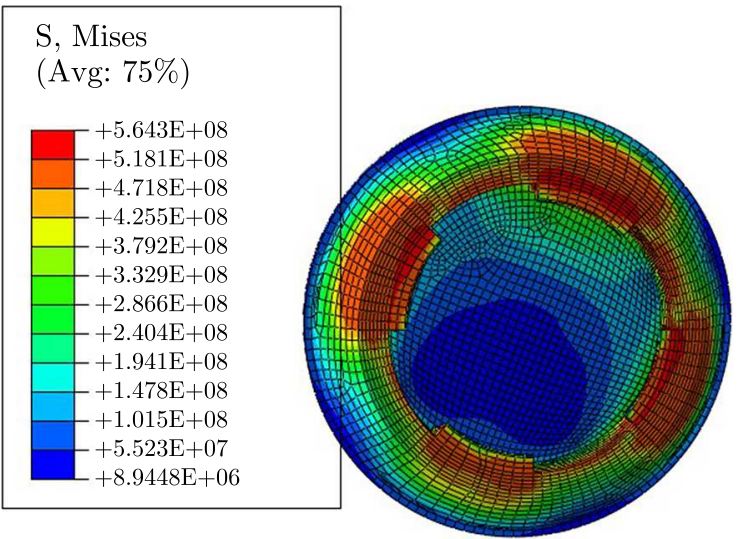

(b)

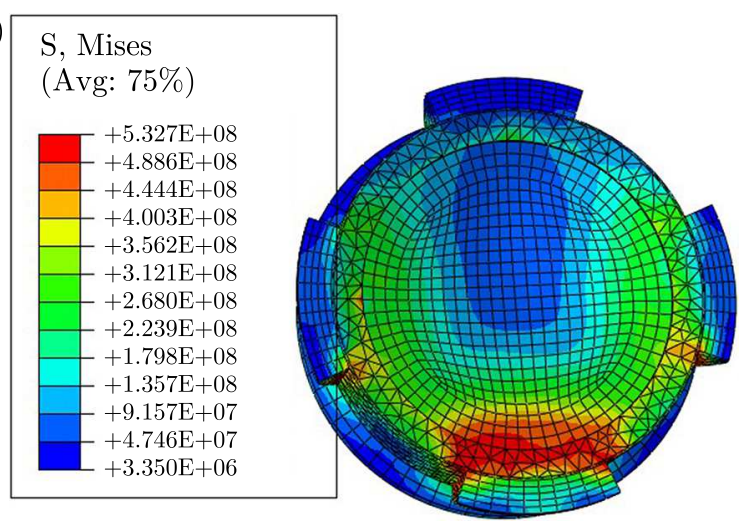

Fig. 9. Stress cloud diagram of each part of the bearing under the combined action of vertical tension and shear force: (a) upper bearing plate, (b) lower bearing plate

Because under the combined action of vertical tension and shear force, the wedge-shaped parts of the upper and lower bearing plates are the most unfavorable force positions of the bearing, so the maximum stress of the wedge-shaped parts of the upper and lower bearing plates was calculated respectively when the inclination angles of the upper and lower bearing plates are $0^{\circ}, 1^{\circ}, 2^{\circ}$ and $3^{\circ}$, as shown in Table 2 . The comparative analysis shows that the wedge-shaped parts of the upper and lower bearings enter the plastic working state, and the stress of the wedge-shaped parts of the upper bearing plate is always larger than that of the lower bearing plate. The most unfavorable working condition is when the upper bearing plate is inclined at $2^{\circ}$.

Table 2. The maximum stress of the wedge-shaped part

\begin{tabular}{|c|c|c|c|}
\hline $\begin{array}{c}\text { Inclination } \\
\text { angle of } \\
\text { upper bearing } \\
\text { plate }\left[^{\circ}\right]\end{array}$ & $\begin{array}{c}\text { Maximum stress of } \\
\text { wedge-shaped part } \\
\text { of upper bearing } \\
\text { plate }[\mathrm{MPa}]\end{array}$ & $\begin{array}{c}\text { Maximum stress of } \\
\text { wedge-shaped part } \\
\text { of lower bearing } \\
\text { plate }[\mathrm{MPa}]\end{array}$ & $\begin{array}{l}\text { Location of } \\
\text { maximum stress }\end{array}$ \\
\hline 0 & 564.0 & $\begin{array}{l}532.7 \\
\end{array}$ & \multirow{4}{*}{$\begin{array}{l}\text { Wedge-shaped } \\
\text { part of upper } \\
\text { bearing plate }\end{array}$} \\
\hline 1 & 569.9 & 532.1 & \\
\hline 2 & 570.2 & 528.3 & \\
\hline 3 & 554.5 & 519.5 & \\
\hline
\end{tabular}




\subsection{The ultimate bearing capacity analysis}

When the upper bearing plate had different inclination angles, the vertical tension of $60000 \mathrm{kN}$ was applied to the upper surface of the upper bearing plate according to the time history (i.e. working state 5). According to the location and time of the failure element, the most unfavorable stress position and ultimate bearing capacity of the bearing under the vertical tension were obtained. The failure of the element is defined when the stress of the element reaches the ultimate strength. Figure 10 shows the distribution of the failure elements of the bearing when the inclination angle of the upper bearing plate is $3^{\circ}$. Table 3 shows the change of the ultimate bearing capacity of the bearing when the inclination angle of the upper bearing plate changes.

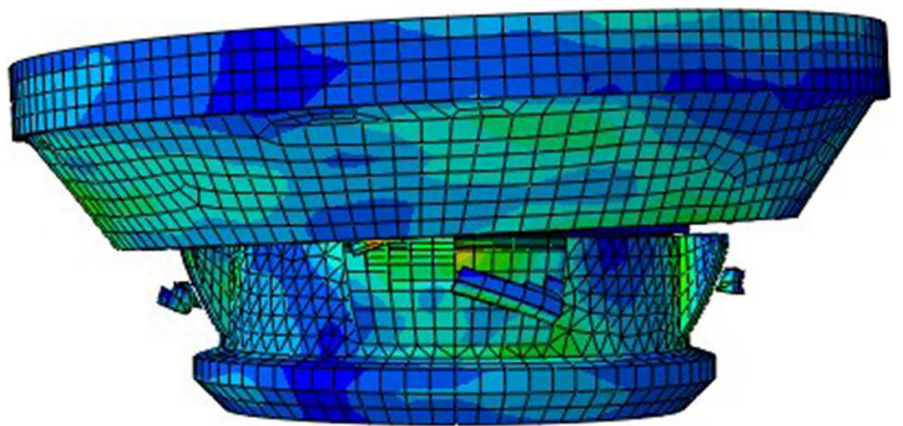

Fig. 10. Distribution of failure elements of the bearing

Table 3. Ultimate bearing capacity of the bearing

\begin{tabular}{|c|c|c|}
\hline $\begin{array}{c}\text { Inclination angle of } \\
\text { upper bearing plate }\left[^{\circ}\right]\end{array}$ & $\begin{array}{l}\text { Maximum vertical } \\
\text { tension }[\mathrm{kN}]\end{array}$ & $\begin{array}{c}\text { Location of } \\
\text { maximum stress }\end{array}$ \\
\hline 0 & $\begin{array}{l}25920 \\
\end{array}$ & \multirow{10}{*}{$\begin{array}{l}\text { Wedge-shaped } \\
\text { part of upper } \\
\text { bearing plate }\end{array}$} \\
\hline 1 & 24069 & \\
\hline 2 & 23467 & \\
\hline 3 & 23066 & \\
\hline 4 & 22063 & \\
\hline 5 & 22564 & \\
\hline 6 & 21060 & \\
\hline 7 & 21060 & \\
\hline 8 & 20458 & \\
\hline 9 & 20458 & \\
\hline
\end{tabular}

According to Table 3, when the inclination angles of the upper bearing plate are different, the ultimate bearing capacities of the bearing are compared. It is found that the bearing is mainly occluded by the wedge-shaped parts of the upper and lower bearing plates under the action of tension. At the same time, with the increase of the inclination angle of the upper bearing plate, the stress of the wedge-shaped part on one side is more concentrated. Therefore, when the inclination angle of the upper bearing plate increases gradually in the range of $0^{\circ}-9^{\circ}$, the bearing capacity of the bearing decreases gradually, and the maximum stress of the bearing appears in the wedge-shaped part of the upper bearing plate. 


\section{Conclusions}

The following conclusions can be drawn from the research presented in this paper:

- Under the action of vertical pressure, the spherical bearing is in the elastic working state. The maximum stress of the bearing appears in the lower bearing plate. The maximum stress is much smaller than the yield strength of the material, which meets the design requirements. The maximum stress of the bearing increases with the increase of the inclination angle of the upper bearing plate.

- Under the action of vertical tension, the maximum stress of the spherical bearing appears in the wedge-shaped part of the upper bearing plate, and the maximum stress of the lower bearing plate is also concentrated in the wedge-shaped part. When the inclination angle of the upper bearing plate is $2^{\circ}$, the bearing stress is up to the largest value. It is suggested that the wedge-shaped part should be strengthened in practical application, and the influence of inclination of the upper bearing plate on the maximum stress of the bearing should be considered.

- Under the combined action of vertical pressure and shear force, the maximum stress of the bearing is larger than that under vertical pressure alone. At the same time, the maximum stress changes with a change of the inclination angle of the upper bearing plate. The change trend of the maximum stress is related to the inclination direction of the upper bearing plate and the relative direction of the shear force. In practical applications, the change of bearing capacity caused by the inclination of the bearing under this working condition should be considered.

- Under the combined action of vertical tension and shear force, the maximum stress of the bearing is larger than that under vertical tension only. This condition is also the most unfavorable condition of the spherical bearing, and the wedge-shaped parts of the upper and lower bearings enter the plastic working state. When the inclination angles of the upper bearing plate are different, the maximum stress of the bearing occurs in the wedge-shaped part of the upper bearing plate, so the reinforcement of this part should be considered in practical application.

- Increasing the vertical tension, it is found that the ultimate bearing capacity of the bearing decreases with the increase of the inclination angle of the upper bearing plate. In practical application, the reduction of the ultimate bearing capacity caused by the possible inclination of the bearing should be considered.

\section{References}

1. BLOCK C., WÖLFEL H.P., 2004, Active vibration isolation of structures with vibration sensitive equipment, IABSE Symposium Shanghai, 88, 5, 42-47

2. China Association for Engineering Construction Standardization, 2008, Technical Specification for Application of Connections of Structural Steel Casting (CECS235: 2008), Beijing

3. Cui L., Xu G.B., 2000, Research and development of universal bearing, universal rotation, anti-seismic, and vibration-damping spherical bearings (in Chinese), Proceedings of the Ninth Space Structure Academic Conference, Xiaoshan, 824-829

4. He W., 2011, Structure Analysis and Fatigue Performance Research on the Bridge Bearing (in Chinese), Master Thesis, Southwest Jiaotong University

5. He W., Wang S.H., WAng G.C., ET AL., 2012, Study on structure and performance of spherical bearing (in Chinese), Railway Engineering, 5, 14-17

6. Huang Q.W., 2018, The Study of Material Constitutive Model for Cast Steel Considering the Effect of Damage Accumulation (in Chinese), Master Thesis, Tianjin University. 
7. Kamenskikh A. A., 2018, The analysis of deformation behavior of antifriction polymeric materials using the example of a spherical bearing, Conference of Young Scientists in Mechanics

8. Li J., 2006, The Structural Design for Super Spherical Bearing (in Chinese), Master Thesis, Dissertation of Chongqing University

9. Liu M., Li J.Y., Chen L., Ju J.S., 2019, On the response and prediction of multi-layered flexible riser under combined load conditions, Engineering Computations, 36, 8, 2507-2529

10. LuO Y. H., Li S.H., XiA J.Y., ET AL., 2013, Research on the structure and performance of tensile ball bearing (in Chinese), Railway Engineering, 3, 46-48

11. Ministry of Housing and Urban-Rural Development of the People's Republic of China, 2016, Code for Seismic Design of Buildings (GB 50011-2010), Beijing

12. Ministry of Housing and Urban-Rural Development of the People's Republic of China, 2018, Standard for Design of Steel Structures (GB 500017-2017), Beijing

13. Ministry of Housing and Urban-Rural Development of the People's Republic of China, 2017, Spherical Bearing for Steel Building (GB/T32836-2016)

14. PAVER A., 2006, Ductility of RBS versus base isolated steel structures, IASS-APCS

15. Peng T.B., Li J.Z., FAn L.C., 2007, Development and application of double spherical aseismic bearing (in Chinese), Journal of Tongji University (Natural Science Edition), 35, 2, 176-180

16. Shao X.D., 2002, Bridge Engineering (in Chinese), First edition, Wuhan

17. Shen D.F., Akesson B., 1998, A FEM-analysis of cracking of a steel bridge, Journal of Suzhou Institute of Urban Construction and Environmental Protection, 11, 3, 18-24

18. Shen Y.L., Fan Z., Zhang P.J., 2011, Analysis of design for spherical bearings in building structures (in Chinese), Steel Construction, 26, 6, 6-11

19. Shi W.X., LiU K.Y., WAng L.Z., 2009, Shaking table test study on damping performance of steel ball-bearing for grid structure (in Chinese), Northwestern Seismological Journal, 31, 4, 344-348

20. Turkington D.H., Carr A.J., Cooke N., Moss P.J., 1989, Design method for bridges on lead-rubber bearings, Journal of Structural Engineering, 115, 12, 3017-3030

21. WAng L.Q., XU G.B., 2002, Application of hyperbolic damping iron bearing in space structure (in Chinese), Steel Construction, 17, 5, 32-34

22. Wang T.Z., Xue S.D., Li X.Y., 2019, Design and mechanical properties analysis for a new type of anti-pulling spherical hinge bearing (in Chinese), Steel Construction, 34, 5, 82-88

23. YAN Z.L., 2013, Structural design and checking calculation of spherical bearing (in Chinese), National Defense Transportation Engineering and Technology, 2, 31-35

24. ZANG X.Q., 2009, Design of spherical bearing adapting to large-tonnage and large-displacement (in Chinese), Railway Engineering, 4, 1-3 